\begin{tabular}{|c|c|c|}
\hline 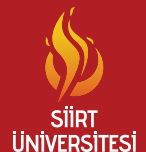 & $\begin{array}{c}\text { Türkiye Tarımsal Araştırmalar Dergisi } \\
\text { dergipark.org.tr/tutad }\end{array}$ & $\begin{array}{l}\text { Turk J Agric Res } \\
\text { 2019, 6(2): 136-141 } \\
\text { @ TÜTAD } \\
\text { ISSN: 2148-2306 } \\
\text { e-ISSN: 2528-858X }\end{array}$ \\
\hline Bdimin Psugunda & Araştırma Makalesi / Research Article & doi: $10.19159 /$ tutad.442319 \\
\hline
\end{tabular}

\title{
Kızılcık (Cornus mas L.) Genotiplerinin Yeşil Çelik İle Çoğaltılması Üzerine Araştırmalar
}

\author{
Mehmet Fikret BALTA $^{1 *}$, İbrahim Ulvi EROL ${ }^{1}$, Koray ÖZRENK $^{2}$, Orhan KARAKAYA ${ }^{1}$, \\ Serkan UZUN ${ }^{1}$ \\ ${ }^{l}$ Ordu Üniversitesi, Ziraat Fakültesi, Bahçe Bitkileri Bölümü, Ordu, TÜRKIYE \\ ${ }^{2}$ Siirt Üniversitesi, Ziraat Fakültesi, Bahçe Bitkileri Bölümü, Siirt, TÜRKIYE
}

\begin{tabular}{|c|c|}
\hline Geliş Tarihi/Received: 10.07 .2018 & Kabul Tarihi/Accepted: 05.04.2019 \\
\hline \multicolumn{2}{|l|}{ ORCID ID (Yazar surasına göre / by author order) } \\
\hline \multicolumn{2}{|c|}{ (D) orcid.org/0000-0002-3859-6490 (DD orcid.org/0000-0003-1246-6580 (DD orcid.org/0000-0002-6692-2337 (DDorcid.org/0000-0003-0783-3120; } \\
\hline (1D) orcid.org/0000-0002-3857-6561 & \\
\hline
\end{tabular}

Öz: Bu çalışma, farklı kızılcık (Cornus mas L.) genotiplerinin yeşil çelik ile çoğaltma olanağının belirlenmesi amacı ile yürütülmüștür. Araștırmanın bitkisel materyalini; ‘44-18', 'Güney uzun', 'Güney yuvarlak', 'Mehmet' ve 'Turgut' genotipleri ile Yalçınkaya-77 standart kızılcık çeşidi oluşturmuştur. Çalışmada yeşil çelikler, incelenen bitkilerden 15 Haziran 2014 tarihinde alınmıştır. Hazırlanan çelikler iki gruba ayrılarak yarısına 3500 ppm indol-3 bütirik asit (IBA) uygulaması yapılmış, diğer yarısına ise herhangi bir uygulama yapılmamıştır (kontrol grubu). Dikimden 5 hafta sonra sökülen kızılcık çeliklerinde köklenme oranı, kalluslenme oranı, en uzun kök, en kısa kök, kök dallanması, yaşayan çelik oranı ve köklenme kalitesi özellikleri incelenmiştir. Çalışmada kontrol grubu çeliklerde incelenen özellikler bakımından kayda değer bir sonuç elde edilememiştir. Araştırma sonucuna göre, IBA uygulanan (3500 ppm) kızılcık yeşil çeliklerinde; köklenme oranı \% 80 ile $\%$ 100, kök sayısı 12.86 adet çelik ${ }^{-1}$ ile 42.94 adet çelik $^{-1}$, kalluslenme oranı $\% 13.30$ ile \% 73.30, en uzun kök boyu $7.74 \mathrm{~mm}$ ile $23.88 \mathrm{~mm}$, en kısa kök boyu $1.39 \mathrm{~mm}$ ile $3.77 \mathrm{~mm}$, köklenme kalitesi 1.56 puan ile 2.93 puan arasında belirlenmiştir. Sonuç olarak, fidan kalitesi üzerine etkili olan köklenme oranı, kök sayısı ve köklenme kalitesi özellikleri "Mehmet" genotipinde diğer genotiplere göre daha yüksek bulunmuştur. Bu genotipin kızılcık meyve türünde yapılacak sslah ve çeşit geliştirme çalışmalarında kullanılması önerilmektedir.

Anahtar Kelimeler: Cornus mas L., çoğaltma, çelik, köklenme, indol-3 bütirik asit

\section{Investigation on Propagation with Softwood Cuttings of Cornelian Cherry (Cornus mas L.) Genotypes}

\begin{abstract}
This study was carried out to determine the possibility of propogation of different cornelian cherry (Cornus mas L.) genotypes. Plant material of research was constituted Yalçınkaya-77 standart cornelian cherry cultivar with '44-18', 'Güney uzun', 'Güney yuvarlak', 'Mehmet' and 'Turgut' genotypes. In the study, softwood cuttings were taken from the examined plants on June 15 2014. Prepared cuttings were divided into two groups and the first group was treated with 3500 ppm indole-3 butyric acid (IBA), while the second groups was not treated with anything (control group). Rooting ratio, callus ratio, longest root, shortest root, root branching, living cutting ratio and rooting quality characteristics of cornelian cherry cuttings removed 5 weeks after planting were investigated. In the study, no significant result was obtained in terms of investigated parameters in cuttings in the control groups. According to the results of the study, the rooting rate of cornelian cherry green cuttings with IBA (3500 ppm) was $80 \%$ to $100 \%$, the number of roots was 12.86 to 42.94 per cutting $^{-1}$, the callus rate was $13.30 \%$ to $73.30 \%$, the longest root length was $7.74 \mathrm{~mm}$ to $23.88 \mathrm{~mm}$, the shortest root length was $1.39 \mathrm{~mm}$ to 3.77 $\mathrm{mm}$, and rooting quality was determined between 1.56 points to 2.93 points. As a result, rooting rate, number of roots and rooting quality characteristics which are effective on nursery tree quality were higher in "Mehmet"genotype compared to other genotypes. This genotype is recommended to be used in breeding and cultivation studies of cornelian chrerry fruit species.
\end{abstract}

Keywords: Cornus mas L., propagation, cutting, rooting, indole-3 butyric acid 


\section{Giriş}

Kızılcık sistematikte Umbelliflorae takımının, Cornaceae familyasının, Cornus cinsi içerisinde yer almaktadır. Türkiye'nin öz meyvelerinden biri olan kızılcık; dünya üzerinde Güneybatı Asya, Orta ve Güneydoğu Avrupa'da yayılış göstermektedir (Ercişli, 2004; Brindza ve ark., 2006). Türkiye'de Akdeniz, Ege, Marmara ve özellikle Karadeniz Bölgesi'nde doğal olarak yetişmekte (Ercişli, 2004); bu bölgelerde kizılcığın tohum ile çoğaltılması sonucunda birbirinden farklı çok sayıda kızılcık genotipi meydana gelmiştir (Yılmaz ve ark., 2009).

Dünya kızılcık üretimi yaklaşık 684 bin tondur. Amerika Birleşik Devletleri, Kanada, Şili, Türkiye ve Azerbaycan dünya kızılcık üretiminde söz sahibi olan ülkelerdir. Türkiye kızılcık üretimi ise yaklaşık 11 bin tondur (Anonymous, 2018). Samsun, Bolu, Bartın, Erzurum ve Balıkesir, Türkiye'de kızılcık üretiminin en fazla yapıldığı iller arasında yer almaktadır (Anonim, 2018). Türkiye dünya kızılcık üretiminde söz sahibi ülkeler arasında olmasına karşın, dünya üretimindeki payı yaklaşık \% 1.6 civarındadır (Anonymous, 2018).

Kızılcık insan sağlığını teşvik eden maddelerce zengin olup, günümüzde modern tıpta kullanılan ve insanlar tarafindan sevilerek tüketilen bir meyve türüdür (Hassanpour ve ark., 2011). Son y1llarda insanların kizılc1k gibi antioksidan ve antosiyaninler bakımından zengin olan meyve türlerine talebi gittikçe artmaktadır (Ercişli ve ark., 2007). İnsanların bu meyve türüne olan ilgisi ve Türkiye'nin dünya kızılcık üretimindeki payının arttırılması için kurulacak olan kapama bahçeler önem arz etmektedir. Bu nedenle Türkiye'de yapılan seleksiyon çalışmaları neticesinde, seçilen kızılcık genotiplerinin ve standart kızılcık çeşitlerinin çoğaltılma olanaklarının belirlenmesi kurulacak olan kapama bahçelerin fidan ihtiyacının karşılanması açısından oldukça önemlidir.

Kızılcığın çoğaltılmasına yönelik bugüne kadar yapılan çalışmalarda tohum ile çoğaltmada genetik açılım göstermesi (Browicz, 1986; Ivanicka, 1989) ve așı ile çoğaltmada așı başarısının düşük olması (Kalkışım, 1997) nedeni ile doku kültürü ve çelik ile çoğaltma yöntemleri kullanılmaktadır. Nitekim Kalkışım (1997) kızılcı̆̆ın hızlı bir şekilde üretilebilmesi için yeşil çelik ve odun çelikleri ile çoğaltılmasının büyük bir avantaj sağlayacağını bildirmektedir.

Bu çalışmada, farklı kızılcık genotiplerinin yeşil çelik ile çoğaltılma olanaklarının belirlenmesi amaçlanmıştır.

\section{Materyal ve Yöntem}

Çalışma, Malatya Meyvecilik Araştırma Enstitüsü'nde bulunan çoğaltma serasında 2014 yılında yürütülmüştür. Çalışmada materyal olarak "Kızılcık Genetik Kaynaklarının Toplanması, Muhafazası ve Değerlendirilmesi Projesi' kapsamında seçilen ‘44-18', 'Güney uzun', 'Güney yuvarlak', 'Mehmet' ve 'Turgut' genotipleri ile Yalçınkaya-77 kızılcık çeşidi kullanılmıştır.

Malatya Meyvecilik Araştırma Enstitüsü'ne ait koleksiyon bahçesinde çeliklerin alınacağı kızılcık bitkileri belirlendikten sonra, bitkiler 15 Şubat 2014 tarihinde sert budamaya tabi tutulmuştur. Çalışmada 15 Haziran 2014 tarihinde 5 kızılcık genotipi (44-18, Güney uzun, Güney yuvarlak, Mehmet, Turgut)'nden ve 1 kızılcık çeşidi (Yalçınkaya-77)'nden yeşil çelikler alınmıştır. Köklendirme ortamı olarak standart tarım perliti (0.0-0.5 mm) kullanılmıştır. Köklendirme ortamının sicaklığ $118-20{ }^{\circ} \mathrm{C}$ ve ortam nemi \% 8090 olacak şekilde ayarlanmıştır. Çalışmada köklendirme hormonu olarak indol-3 bütirik asit (IBA) kullanılmıştır. IBA dozunun seçiminde, Kalyoncu ve ark. (2008a)'nın kızılcık ile yaptığ 1 köklendirme çalışması referans alınmıştır. Çelikler, kızılcık bitkilerinin y1llık sürgünlerinden sabah erken saatlerde alınmış ve $15-20 \mathrm{~cm}$ boyunda olacak şekilde hazırlanmıştır. Hazırlanan çelikler iki gruba ayrılarak yarısına 3500 ppm IBA uygulanmış, diğer yarısına ise herhangi bir uygulama yapılmadan kontrol grubu olarak ayrılmıştır. Daha sonra hazırlanan çelikler 2/3'lük kısmı köklendirme ortamında kalacak şekilde köklendirme tavalarına dikilmiştir. Çalışma, tesadüf parselleri deneme desenine göre 4 tekerrürlü ve her tekerrürde 15 adet bitki olacak şekilde dizayn edilmiştir.

Dikimi yapılan çeliklerde 5 hafta sonra (20 Temmuz 2014) söküm işlemi gerçekleştirilmiştir. Sökümü yapılan kızılcık genotiplerine ait çeliklerde, Kalyoncu (1996) ve Kalyoncu ve ark. (2008a) tarafindan bildirilen esaslara göre köklenme oranı (\%), kök sayısı (adet çelik ${ }^{-1}$ ), kalluslenme oranı (\%), en uzun ve en kısa kök boyu (mm), kök dallanması (adet çelik ${ }^{-1}$ ) ve yaşayan çelik oranı (\%); Kantarc1 ve Ayfer (1989), Özcan (1993) ve Pirlak (1997) tarafindan belirtilen esaslar dâhilinde, köklenen çeliklerde 1-3 (1-zayıf, 2-orta, 3-iyi) skalasına göre de köklenme kalitesi belirlenmiştir.

Verilerin değerlendirilmesinde MINITAP 17 istatistik programı kullanılmıştır. Ortalamalar arasındaki farklılık Tukey çoklu karşılaştırma yöntemi kullanılarak belirlenmiştir. 


\section{Bulgular ve Tartışma}

Araştırmada, kızılcık genotiplerine ait yeşil çeliklerde; köklenme oranı, kök sayısı, en uzun ve en kısa kök boyu, kalluslenme oranı, yaşayan çelik oran1, kök kalitesi ve kök dallanmasına kontrol ve 3500 ppm IBA uygulamalarının etkisine ait veriler Tablo 1-4'te sunulmuştur.

\subsection{Köklenme oranı}

Çalışmada; IBA uygulanmış kızılcık genotipleri arasında köklenme oranı bakımından istatistiksel olarak önemli $(\mathrm{p}<0.05)$ farklılık görülürken, hiçbir uygulamanın yapılmadığı kontrol konusunda yeşil çeliklerde köklenmenin olmadığ Bunun yanı sıra IBA uygulamasında 'Güney uzun', 'Mehmet' ve 'Turgut' genotipleri ile Yalçınkaya-77 çeşidi arasında köklenme oranı bakımından istatistiksel olarak farklılık görülmemiştir. IBA uygulamasında köklenme oranı \% 80 (Güney yuvarlak) ile \% 100 (Güney uzun, Mehmet, Turgut ve Yalçınkaya-77) arasında değişiklik göstermiştir (Tablo 1).

Tablo 1. Haziran ayında alınan yeşil çeliklerin köklenme oranı ve kök sayısı*

\begin{tabular}{lcrcc}
\hline \multirow{2}{*}{ Genotipler } & \multicolumn{2}{c}{$\begin{array}{c}\text { Köklenme oran1 } \\
(\%)\end{array}$} & \multicolumn{2}{c}{$\begin{array}{c}\text { Kök say1s1 } \\
\left(\text { adet çelik }^{-1}\right)\end{array}$} \\
\cline { 2 - 5 } & Kontrol & $\begin{array}{r}3500 \\
\text { ppm }\end{array}$ & Kontrol & $\begin{array}{c}3500 \\
\text { ppm }\end{array}$ \\
\hline '44-18' & 0 & $93 \mathrm{~b}$ & 0 & $26.60 \mathrm{~b}$ \\
'Güney uzun' & 0 & $100 \mathrm{a}$ & 0 & $25.00 \mathrm{~b}$ \\
'Güney yuvarlak' & 0 & $80 \mathrm{c}$ & 0 & $25.06 \mathrm{~b}$ \\
'Mehmet' & 0 & $100 \mathrm{a}$ & 0 & $42.94 \mathrm{a}$ \\
'Turgut' & 0 & $100 \mathrm{a}$ & 0 & $38.40 \mathrm{a}$ \\
Yalçınkaya-77 & 0 & $100 \mathrm{a}$ & 0 & $12.86 \mathrm{c}$ \\
\hline
\end{tabular}

*: Aynı sütunda aynı harf ile gösterilen ortalamalar arasındaki farklılık istatistiksel olarak önemsizdir $(\mathrm{p}<0.05)$

Kızılcıkta yeşil çelik ile yapılan çoğaltma çalışmalarında köklenme oranını, Kalyoncu (1996) 4000 ppm IBA uygulamasında \% 90, kontrol uygulamasında ise ortalama \% 40 olarak; Yavaş (2000) 4000 ppm IBA uygulanan çeliklerde \% 100, kontrol grubunda ise \% 25; Kalyoncu ve ark. (2008a) 3500 ppm IBA uygulamasinda \% 86.70-\% 100, kontrol grubunda ise \% $53.30-\% \quad 93.30$ arasında değişen oranda; Yavuz (2015) 6 farklı kızılc1k genotipinde 3500 ppm IBA uygulamasında $\%$ 40-\% 100, kontrol grubunda ise \% 20-\% 90 arasında olduğunu tespit etmişlerdir. Çeliklerde kök oluşumu üzerine ana bitkinin beslenme durumu ve yaşı (Hartmann ve ark., 1990; Cristofori ve ark., 2010), çeliklerin ağaç üzerinde alındığ1 yer (Erdoğan ve Aygün, 2006), çelik alma zamanı, çelik yaşı, genotip (Yıldız ve ark., 2009) ve hormon uygulamalarının (Kalyoncu, 1996; Azad ve ark., 2016) önemli bir etkisi bulunmaktadır. Kalyoncu (1996) hormon uygulamaları ile çeliklerde kök oluşumu için gerekli olan kalluslenmenin azaldığını ve hormon uygulamasının etkisi ile direk kök oluşumunun meydana geldiğini ifade etmektedir. Mevcut çalışmada da IBA uygulanmış çeliklerde köklenme oranının yüksek olduğu, buna karşılık kalluslenme oranının ise düşük olduğu görülmektedir. Bunun yanı sıra, kontrol grubu çeliklerinde ise tersi bir durum söz konusudur. Çalışmada köklenme oranı bakımından görülen farklılıkların genotipten ve çeliklerin bitki üzerinde alındığı yerden kaynaklı olabileceği düşünülmektedir.

\subsection{Kök sayısı}

Kök sayısı çeliklerde kök kalitesini ve köklenen çeliklerin daha sonraki aşamada performansını etkileyen önemli bir özelliktir (Yıldız ve ark., 2009). Kök sayısı bakımından, araştırmada ele alınan kızılcık genotipleri arasında yalnızca IBA uygulamasında istatistiksel olarak $\mathrm{p}<0.05$ düzeyinde önemli farklılık tespit edilmiştir. IBA uygulamasında kök sayısı bakımından, istatistiksel olarak ayn grupta yer alan 'Turgut' ile 'Mehmet' genotipleri en yüksek değerleri gösterirken, bunları '44-18', 'Güney uzun' ile 'Güney yuvarlak' genotipleri takip etmiştir. IBA uygulamasında kök sayısı 12.86 adet çelik ${ }^{-1}$ (Yalçınkaya-77) ile 42.94 adet çelik ${ }^{-1}$ ('Mehmet') arasında belirlenmiştir (Tablo 1).

Kök sayısını Kalyoncu (1996) kızılcık yeşil çeliklerinde 4000 ppm IBA uygulamasında 509.0 adet çelik ${ }^{-1}$, kontrol uygulamasında 42.88 adet çelik ${ }^{-}$ 1; Yavaş (2000) Gilaboru yeşil çeliklerinde 3500 ppm IBA uygulamasında 135.20 adet çelik ${ }^{-1}$, kontrol uygulamasında 52.80 adet çelik $^{-1}$, Kalyoncu ve Ecevit (1995) 3500 ppm IBA uygulanmış kızılcık yeşil çeliklerinde 56.13 adet çelik ${ }^{-1}$, kontrol uygulamasında ise 6.27 adet çelik ${ }^{-1}$; Kalyoncu ve ark. (2008a) 3500 ppm IBA uygulanmış kızılcık yeşil uç çeliklerinde 9.33 adet çelik-1, kontrol uygulamasında ise 1.33 adet çelik ${ }^{-1}$; Özyurt ve ark. (2012) mahlep yeşil çeliklerinde 2500 ppm IBA uygulamasında 2.1-9.7 adet çelik $^{-1}$ olarak belirlemişlerdir. Köklenmiş çeliklerde kök sayısı üzerine hormon uygulamalarının (Cristofori ve ark., 2010; Azad ve Matin, 2015), çelik yaşının ve çeşidin (Cristofori ve ark., 2010) önemli bir etkisinin olduğu bildirilmektedir. Nitekim araştırmamızda da kök sayısına ait bulguların araştırıcıların bulgularından farklılık göstermesi çalışmada kullanılan genotip ve çeşitten kaynaklı olabileceği düşünülmektedir.

\subsection{Kalluslenme oranı}

Kalluslenme oranının çeliklerde köklenme oranı etkileyen önemli bir özellik olduğu bildirilmektedir (Kalyoncu, 1996; Kalyoncu ve ark., 2008a). 
Araştırmada, IBA uygulanmış farklı kızılcık genotipleri arasında kalluslenme oranı bakımından istatiksel olarak $\mathrm{p}<0.05$ düzeyinde önemli farklılık belirlenirken, kontrol uygulamasında genotipler arasındaki farklılık önemsiz çıkmıştır. IBA uygulamasında en yüksek kalluslenme oranı \% 73.3 ile 'Yalçınkaya-77'çeşidinde tespit edilmiş; en düşük kalluslenme oranına sahip 'Mehmet' (\% 13.3) genotipi hariç, 'Yalçınkaya-77'çeşidi ile diğer genotipler arasında kalluslenme oranı bakımından ortaya çıkan farklılık istatistiksel olarak önemsiz bulunmuştur (Tablo 2).

Tablo 2. Haziran ayında alınan yeşil çeliklerin kalluslenme ve köklenme oranı*

\begin{tabular}{|c|c|c|c|c|}
\hline \multirow{2}{*}{ Genotipler } & \multicolumn{2}{|c|}{$\begin{array}{c}\text { Kalluslenme } \\
\text { oranı }(\%)\end{array}$} & \multicolumn{2}{|c|}{$\begin{array}{c}\text { Yaşayan çelik } \\
\text { oranı }(\%)\end{array}$} \\
\hline & Kontrol & $\begin{array}{l}3500 \\
\text { ppm }\end{array}$ & Kontrol & $\begin{array}{l}3500 \\
\text { ppm }\end{array}$ \\
\hline '44-18' & $80 \mathrm{a}$ & $30 \mathrm{ab}$ & 100 & 100 \\
\hline ‘Güney uzun’ & $80 \mathrm{a}$ & $46.6 \mathrm{ab}$ & 100 & 100 \\
\hline 'Güney yuvarlak' & $100 \mathrm{a}$ & $20 \mathrm{ab}$ & 100 & 100 \\
\hline 'Mehmet' & $80 \mathrm{a}$ & $13.3 \mathrm{~b}$ & 100 & 100 \\
\hline 'Turgut' & $100 \mathrm{a}$ & $53.3 \mathrm{ab}$ & 100 & 100 \\
\hline Yalçınkaya-77 & $80 \mathrm{a}$ & $73.3 \mathrm{a}$ & 100 & 100 \\
\hline
\end{tabular}

Kalyoncu (1996) kızılcık bitkisinde yeşil çelik ile yaptığı çoğaltma çalışmasında kalluslenme oranını 4000 ppm IBA uygulamasinda \% 12 , kontrol uygulamasinda \% 85; Kalyoncu ve ark. (2008a) kızılcık yeşil uç çeliklerinde kalluslenme oranını 3500 ppm uygulamasında \% 40, kontrol uygulamasında ise \% 66.7 olarak bulmuşlardır. Farklı meyve türlerinde yeşil çelik ile yapılan çalışmalarda kalluslenme oranını Özer ve Kalyoncu (2007) gilaboru bitkisinde kontrol grubu çeliklerde $\%$ 85, 3500 ppm IBA uygulamasinda ise \% 20; Kalyoncu ve ark. (2008b) mahlepte 3500 ppm IBA uygulamasında \% 43.75, kontrol grubu çeliklerde ise \% 79.16 olarak belirlemişlerdir. Kalyoncu (1996) çeliklerde kök oluşumunun olmadığ1 durumlarda kalluslenme oranının arttığını ve hormon uygulamalarının ise kök oluşumunu arttırdığı için kalluslenmeyi azalttığını bildirmiştir. Nitekim, bu durumunun bir sonucu olarak mevcut çalışmada da kalluslenme oranı kontrol grubu çeliklerinde IBA uygulanmış çeliklere göre daha yüksek bulunmuştur. Çalışmada kalluslenme oranı bakımından elde edilen bulgular araştırıcıların bulguları ile benzerlik göstermektedir.

\subsection{Yaşayan çelik oranı}

Kamaluddin ve Ali (1996) özellikle yeşil ve yarı odun çelikler ile yapılan çoğaltma çalışmalarında yaşayan çelik oranının yüksek olması için ortam neminde meydana gelebilecek kayıpların minimum düzeyde tutulması gerektiğini ifade etmektedirler.
Bunun yanı sıra, Kalyoncu (1996) çeliklerde kallus oluşumunun, Baul ve ark., (2010) ise çelikte bulunan doğal oksin içeriğinin yaşayan çelik oranı üzerine etki ettiğini bildirmişlerdir. Çalışmada yaşayan çelik oranı bakımından uygulamalar arasında istatistiksel olarak bir farklılık görülmemiş; tüm uygulamalarda yaşayan çelik oranı incelenen k1zılc1k genotiplerinde \% 100 olarak tespit edilmiştir (Tablo 2).

Yeşil çelik ile yapılan çoğaltma çalışmalarında, yaşayan çelik oranının; Ivanicka ve Cvopa (1977) kızılcıkta \% 70-\% 98 arasında değişim gösterdiğini, Özer ve Kalyoncu (2007) gilaboruda tüm uygulamalarda \% 100, Kalyoncu ve ark. (2008a) kızılc1kta kontrol ve 3500 ppm IBA uygulamasinda \% 100 olduğunu, Yavuz (2015) farklı kızılcık genotiplerinde kontrol uygulamasinda $\% 10-\% 70$, 3500 ppm IBA uygulamasında ise \% 10-\% 60 arasında değiştiğini rapor etmişlerdir. Yaşayan çelik oranı bakımından elde ettiğimiz bulgular araştırıcıların bulguları ile uyum içerisindedir.

\subsection{En uzun kök boyu ve en kısa kök boyu}

Kök uzunluğu köklenen çeliklerde kök kalitesinin belirlemesinde kullanılan önemli bir özelliktir (Yıldız ve ark., 2009). İncelenen kızılcık genotiplerinde en uzun kök boyu ve en k1sa kök boyu bakımından IBA uygulamasında istatistiksel olarak $\mathrm{p}<0.05$ düzeyinde önemli farkl111k belirlenmiştir. Bunun yanı sıra, en kısa kök boyu bakımından 'Güney uzun' genotipi hariç diğer genotipler ile 'Yalçınkaya-77'çeşidi arasında istatistiksel olarak farklılık görülmemiştir. IBA uygulamasında en uzun kök boyu $7.74 \mathrm{~mm}$ (Yalçınkaya-77) ile $23.88 \mathrm{~mm}$ ('Mehmet') arasında, en kısa kök boyu ise $1.39 \mathrm{~mm}$ ('Güney uzun') ile $3.77 \mathrm{~mm}$ ('Mehmet') arasında ölçülmüştür (Tablo 3).

Tablo 3. Haziran ayında alınan yeşil çeliklerin en uzun kök ve en kısa kök boyu*

\begin{tabular}{lcccc}
\hline & $\begin{array}{c}\text { En uzun kök boyu } \\
(\mathrm{mm})\end{array}$ & $\begin{array}{c}\text { En kisa kök boyu } \\
(\mathrm{mm})\end{array}$ \\
\cline { 2 - 5 } Genotipler & Kontrol & $\begin{array}{c}3500 \\
\mathrm{ppm}\end{array}$ & Kontrol & $\begin{array}{c}3500 \\
\mathrm{ppm}\end{array}$ \\
\hline '44-18' & 0 & $14.32 \mathrm{~b}$ & 0 & $1.89 \mathrm{ab}$ \\
'Güney uzun' & 0 & $12.62 \mathrm{~b}$ & 0 & $1.39 \mathrm{~b}$ \\
'Güney yuvarlak' & 0 & $10.61 \mathrm{bc}$ & 0 & $1.74 \mathrm{ab}$ \\
'Mehmet' & 0 & $23.88 \mathrm{a}$ & 0 & $3.77 \mathrm{a}$ \\
'Turgut' & 0 & $12.56 \mathrm{~b}$ & 0 & $1.96 \mathrm{ab}$ \\
Yalçınkaya-77 & 0 & $7.74 \mathrm{c}$ & 0 & $1.80 \mathrm{ab}$ \\
\hline *: Aynı sütunda aynı harf ile gösterilen ortalamalar arasındaki farkl11ık \\
istatistiksel olarak önemsizdir (p<0.05)
\end{tabular}

Yeşil çelik ile yapılan çalışmalarda en uzun kök boyunu ve en kisa kök boyunu sirasıyla; Kalyoncu ve Ecevit (1995) kizılc1kta kontrol grubu çeliklerinde $21.75 \mathrm{~mm}$ ve $7.79 \mathrm{~mm}, 4000 \mathrm{ppm}$ IBA 
uygulamasında ise $99.39 \mathrm{~mm}$ ve $30.73 \mathrm{~mm}$; Özer ve Kalyoncu (2007) gilaboruda kontrol grubu çeliklerinde $68.0 \mathrm{~mm}$ ve $3.0 \mathrm{~mm}, 3500 \mathrm{ppm}$ IBA uygulamasında ise $67.0 \mathrm{~mm}$ ve $6.0 \mathrm{~mm}$; Kalyoncu ve ark. (2008a) kızılcıkta yeşil uç çelikleri ile yaptığı çalışmada kontrol grubunda $7.07 \mathrm{~mm}$ ve $2.20 \mathrm{~mm}, 3500 \mathrm{ppm}$ IBA uygulamasinda ise 11.20 $\mathrm{mm}$ ve $2.80 \mathrm{~mm}$ olarak belirlerken; Yavuz (2015) farklı k1zılcık geotiplerinde en uzun kök boyunu 3500 ppm IBA uygulamasinda $8.50-14.00 \mathrm{~mm}$, kontrol grubunda ise 2.48-4.10 $\mathrm{mm}$ arasında ölçmüştür. Farklı araştırıcılar (Husen ve Pal, 2006; Baul ve ark., 2010) çeliklerde kök boyu üzerine çelikte bulunan az miktardaki doğal oksin hormonunun etki ettiğini bildirmişlerdir. Bunun yanı sıra IBA uygulamasının çeliklerde kök boyu üzerine etki eden önemli bir faktör olduğu bildirilmektedir (Azad ve Matin, 2015). Nitekim çalışmamızda da kontrol grubu çeliklerine kıyasla hormon uygulamasının kök boyu üzerine önemli bir etkisinin olduğu görülmüştür. IBA uygulamasında görülen bazı farklılıkların ise genotipten ve çeliklerin içerdiği oksin miktarından kaynaklı olabileceği düşünülmektedir.

\subsection{Köklenme kalitesi}

Köklenme kalitesi kök oluşumu gerçekleşen çeliklerin köklenme ortamından alındıktan sonraki performansını etkileyen önemli bir özelliktir (Yıldız ve ark., 2009). Köklenme kalitesi bakımından, IBA uygulanmış çeliklerde istatistiksel olarak önemli farkl1lık tespit edilmiştir $(\mathrm{p}<0.05)$ IBA uygulamasında, köklenme kalitesi bakımından 2.93 puanla 'Mehmet' genotipi en yüksek değere sahip olurken; 'Mehmet' genotipinin köklenme kalitesi puanı ile '44-18', 'Güney yuvarlak' ve 'Turgut' genotiplerinin puanları arasındaki farklılık istatistik olarak önemsiz çıkmıştır. Çalışmada, 1.56 puanla 'Yalçınkaya-77'çeşidi ve 1.60 puanla 'Güney uzun' genotipi en düşük değere sahip olmuştur (Tablo 4). Pırlak (1997) farklı kızılcık genotiplerinde odun çelikleri ile yaptığı çalışmada en yüksek köklenme kalitesini IBA'nın yüksek dozları uygulanmış çeliklerde, en düşük ise kontrol grubu çeliklerinde tespit etmiştir. Bu bakımdan elde ettiğimiz bulgular Pırlak (1997)'ın bulguları ile benzerlik göstermektedir.

\subsection{Kök dallanması}

Araştırma sonuçlarına göre, kök oluşumunun meydana geldiği 3500 ppm IBA uygulanmış kızılcık çeliklerinde kök dallanması olmamıştır (Tablo 4). Kalyoncu ve ark. (2008a) kızılcıkta yeşil uç çelikleri ile yaptığı çoğaltma çalışmasında, çeliklerde kök dallanmasının olmadığını; Yavuz (2015) farklı kızılcık genotiplerinin yeşil uç çeliklerinde kök dallanmasını kontrol grubu çeliklerinde 2.25-4.0 adet, 3500 ppm IBA uygulaması yapılmış çeliklerde ise 18.0-22.0 adet arasında değişiklik gösterdiğini belirlemiştir. Kök dallanması bakımından elde ettiğimiz veriler Kalyoncu ve ark. (2008a)'nın bulguları ile benzerlik göstermektedir. Görülen farklılıkların ise genotipten kaynaklı olabileceği düşünülmektedir.

Tablo 4. Haziran ayında alınan yeşil çeliklerin köklenme kalitesi ve kök dallanması ${ }^{*}$

\begin{tabular}{lcccc}
\hline \multirow{2}{*}{ Genotipler } & $\begin{array}{c}\text { Köklenme } \\
\text { kalitesi (1-3) }\end{array}$ & $\begin{array}{r}\text { Kök dallanması } \\
\text { (adet çelik }{ }^{-1} \text { ) }\end{array}$ \\
\cline { 2 - 5 } & Kontrol & $\begin{array}{c}3500 \\
\text { ppm }\end{array}$ & Kontrol & $\begin{array}{c}3500 \\
\text { ppm }\end{array}$ \\
\hline '44-18' & 0 & $\begin{array}{c}2.00 \mathrm{ab} \\
1.60 \mathrm{~b}\end{array}$ & 0 & 0 \\
'Güney uzun' & 0 & $2.00 \mathrm{ab}$ & 0 & 0 \\
'Güney yuvarlak' & 0 & $2.93 \mathrm{a}$ & 0 & 0 \\
'Mehmet' & 0 & $1.86 \mathrm{ab}$ & 0 & 0 \\
'Turgut' & 0 & $1.56 \mathrm{~b}$ & 0 & 0 \\
Yalçinkaya-77 & 0 &
\end{tabular}

*: Aynı sütunda aynı harf ile gösterilen ortalamalar arasındaki farklılık istatistiksel olarak önemsizdir $(\mathrm{p}<0.05)$

\section{Sonuçlar}

Farklı kızılcık genotiplerinin yeşil çelik ile çoğaltma olanaklarının araştırıldığı bu çalışmada; kontrol grubu çeliklerine göre IBA uygulanmış çeliklerde incelenen parametreler bakımından daha iyi sonuçlar elde edilmiştir. $\mathrm{Bu}$ durum kızılcık bitkisinin ticari olarak çoğaltılması durumunda hormon kullanılmasının gerekli olduğunu göstermektedir. Fidan kalitesi üzerine etkili olan köklenme oranı, kök sayısı ve köklenme kalitesi özellikleri 'Mehmet' genotipinde diğer genotiplere göre daha yüksek bulunmuştur. Bunun yanı sıra Yalçınkaya-77 çeşidi ve diğer genotiplere göre köklenme oranının düşük olduğu ‘44-18' ve ‘Güney yuvarlak' genotiplerinde farklı dönemlerde alınacak yeşil çeliklerin köklenme oranını arttıracağı düşünülmektedir. Bu nedenle '44-18' ve 'Güney yuvarlak' genotiplerinde 5 ve 10 Haziran tarihlerinde alınacak yeşil çelikler ile çoğaltma çalışmalarının yürütülmesi önerilmektedir. Ayrıca köklenme özellikleri bakımından Yalçınkaya-77 standart kızılcık çeşidine göre daha iyi sonuçlar veren 'Mehmet' genotipinin kızılcık meyve türünde yapılacak ıslah ve çeşit geliştirme çalışmalarında kullanılması önerilmektedir.

\section{Kaynaklar}

Anonim, 2018. Bitkisel Üretim İstatistikleri. Türkiye İstatistik Kurumu, (http://www.tuik.gov.tr/), (Erişim tarihi: 21.06.2018)

Anonymous, 2018. Crops Production Quality. (http:// www.fao.org/home/en/), (Erişim tarihi: 21.06.2018).

Azad, M.S., Alam, M.J., Mollick, A.S., Matin, M.A., 2016. Responses of IBA on rooting, biomass production and survival of branch cuttings of 
Santalum album L. a wild threatened tropical medicinal tree species. Journal of Science, Technology and Environment Informatics, 2(3): 195206.

Azad, M.S., Matin, M.A, 2015. Effect of indole-3-butyric acid on clonal propagation of Swietenia macrophylla through branch cutting. Journal of Botany, 1: 1-7.

Baul, T.K., Mezbahuddin, M., Hossain, M.M., Mohiuddin, M., 2010. Vegetative propagation of Holarrhena pubescens, a wild tropical medicinal plant: effect of indole-3-butyric acid (IBA) on stem cuttings. Forestry Studies in China, 12(4): 228-235.

Brindza, P., Brindza, J., Tóth, D., Klimenko, S.V., Grigorieva, O., 2006. Biological and commercial characteristics of cornelian cherry (Cornus mas L.) population in the Gemer region of Slovakia. Acta Horticulturae, 818(1): 85-94.

Browicz, K., 1986. Chorology of Trees and Shrubs in South-West Asia and Adjacent Regions. Poznan, Poland.

Cristofori, V., Rouphael, Y., Rugini, E., 2010. Collection time, cutting age, IBA and putrescine effects on root formation in Corylus avellana L. cuttings. Scientia horticulturae, 124(2): 189-194.

Ercişli, S., 2004. Cornelian Cherry germplasm resources of Turkey. Journal of Fruit and Ornamental Plant Research Special, 12: 87-92.

Ercişli, S., Orhan, E., Özdemir, O., Şengül, M., 2007. The genotypic effects on the chemical composition and antioxidant activity of sea buckthorn (Hippophae rhamnoides L.) berries grown in Turkey. Scientia Horticulturae, 115(1): 27-33.

Erdoğan, V., Aygün, A., 2006. Kara dutun (Morus nigra L.) yeşil çelikle çoğaltılması üzerine bir araştırma. II. Ulusal Üzümsü Meyveler Sempozyumu, Bildiriler Kitab1, 14-16 Eylül, Tokat, s. 172-175.

Hartmann, H.P., Kester, D.E., Davies, J.T., 1990. Plant Propagation: Principle and Practices. Prentice-Hall, New Jersey.

Hassanpour, H., Yousef, H., Jafar, H., Mohammad, A., 2011. Antioxidant capacity and phytochemical properties of cornelian cherry (Cornus mas L.) genotypes in Iran. Scientia Horticulturae, 129(3): 459-463.

Husen, A., Pal, M., 2006. Variation in shoot anatomy and rooting behaviour of stem cuttings in relation to age of donor plants in teak (Tectona grandis Linn. f.). New Forests, 31(1): 57-73.

Ivanicka, J., 1989. Propagation of unusual fruit crops from softwood cuttings under mist. Vedecke Prace Vyskumneho Ustavu Ovocnych a Okrasnych Drevin v Bojniciach, 7(2): 163-170.

Ivanicka, J., Cvopa, J., 1977. Propagation of dogwood (Cornus mas L.) by softwood and semi-hardwood cuttings. Gartenbauwissenchaft, 42(4): 169-171.

Kalkışım, Ö., 1997. Kızılcıkta aşı kaynaşması ile çelik köklenmesinin anatomik ve histolojik olarak incelenmesi üzerine bir araştırma. Doktora tezi, Yüzüncü Y1l Üniversitesi Fen Bilimleri Enstitüsü, Van.

Kalyoncu, H., 1996. Konya yöresindeki kızılcık (Cornus mas L.) tiplerinin bazı özellikleri ve farklı nem ortamlarındaki köklenme durumu üzerine bir araştırma. Doktora tezi, Selçuk Üniversitesi Fen Bilimleri Enstitüsü, Konya.

Kalyoncu, H., Ecevit, F.M., 1995. Farkl1 nem seviyelerinin kızılcık (Cornus mas L.) yeşil çeliklerinde köklenme üzerine etkileri. Türkiye II. Ulusal Bahçe Bitkileri Kongresi, Bildiriler Kitab1, 36 Ekim, Adana, s. 273-276.

Kalyoncu, H., Ersoy, N., Y1lmaz, M., 2008a. Kızılcık (Cornus mas L.) yeşil uç çeliklerinin köklenmesi üzerine farklı IBA dozları ve nem seviyelerinin etkileri. Selçuk Üniversitesi Ziraat Fakültesi Dergisi, 22(46): 62-67.

Kalyoncu, H,. Ersoy, N., Aydın, M., 2008b. Mahlep (Prunus mahaleb L.) yeşil uç çeliklerinin köklenmesi üzerine farklı IBA dozları ve nem seviyelerinin etkisi. Süleyman Demirel Üniversitesi Ziraat Fakültesi Dergisi, 3(1): 32-41.

Kamaluddin, M., Ali, M., 1996. Effects of leaf area and auxin on rooting and growth of rooted stem cuttings of neem. New Forests, 12(1): 11-18.

Kantarc1, M., Ayfer, M., 1989. Bazı önemli findık çeşitlerimizin çelikle çoğaltılmaları üzerinde araştırmalar. Doğa Türk Tarım ve Ormancilık Dergisi, 13(3b): 1096-1109.

Özcan, M., 1993. "Hayward” ve "Matua" kivi çeşitlerinin odun çeliklerinin köklenmeleri üzerine IBA dozlarının ve çelik alma zamanlarının etkileri. Bahçe, 22(1-2): 85-90.

Özer, E, Kalyoncu, H., 2007. Gilaburu (Viburnum opulus L.)'nun yeşil çelikle çoğaltma imkânlarının araştırılması. Selçuk Üniversitesi Ziraat Fakültesi Dergisi, 21(43): 46-52.

Özyurt, İ., Demirsoy, H., Akça, Y., 2012. Bazı mahlep (Prunus mahaleb L.) genotiplerinin ve SL64 anacinın çelikle çoğaltılabilme özellikleri. Gaziosmanpaşa Bilimsel Araştırma Dergisi, 15(1): 90-96.

Pırlak, L., 1997. Kızılcıkta (Cornus mas L.) çelik alma zamanlarının ve IBA uygulamalarının yeşil çeliklerin köklenmeleri üzerine etkileri. Atatürk Üniversitesi Ziraat Fakültesi Dergisi, 28(3): 369-380.

Yavaş, A., 2000. Tokat'ta kızılcık'ın (Cornus mas L.) yeşil ve odun çelikleri ile çoğaltılması üzerine bir araştırma. Yüksek lisans tezi, Gaziosmanpaşa Üniversitesi Fen Bilimleri Enstitüsü, Tokat.

Yavuz, C,. 2015.,Malatya ili'nden selekte edilen bazı kızılcık (Cornus mas L.) genotiplerinde farklı IBA uygulamalarının yeşil çeliklerin köklenmesi üzerine etkileri. Yüksek lisans tezi, Kahramanmaraş Sütçü İmam Üniversitesi Fen Bilimleri Enstitüsü, Kahramanmaraş.

Yıldız, K., Çekiç, Ç., Güneş, M., Özgen, M., Özkan, Y., Akça, Y., Gerçekçioğlu, R., 2009. Farklı dönemlerde alınan kara dut (Morus nigra L.) çelik tiplerinde köklenme başarısının belirlenmesi. Gaziosmanpaşa Üniversitesi Ziraat Fakültesi Dergisi, 1: 1-5.

Yılmaz, K.U., Ercişli, S., Zengin, Y., Şengül, M., Kafkas, E.Y., 2009. Preliminary characterisation of cornelian cherry (Cornus mas L.) genotypes for their physicochemical properties. Food Chemistry, 114(2): 408412 . 